Article

\title{
Positional Analysis: A Multidimensional and Democracy-Oriented Approach to Decision-Making and Sustainability
}

\author{
Peter Söderbaum $\mathbb{D}$ \\ School of Business, Society and Engineering, Mälardalen University, 72123 Västerås, Sweden; \\ peter.soderbaum@mdh.se
}

Received: 12 May 2020; Accepted: 30 June 2020; Published: 10 July 2020

\begin{abstract}
Essential principles of democracy are threatened in many parts of the world. In mainstream economics textbooks, reference to democracy is marginal or non-existent. At issue is if economics as a discipline can contribute to strengthen democracy in policy-making and decision situations more generally. In this essay, it is proposed that democracy becomes part of the definition of economics. While mainstream neoclassical cost-benefit analysis (CBA) is criticized as being technocratic, positional analysis (PA) connected with institutional ecological economics is advocated and presented with its essential elements. While a specific ideological orientation with emphasis on markets is built into CBA, PA represents an attempt to identify more than one ideological orientation or narrative as relevant among actors related to an issue. This is part of an attempt to carry out a many-sided analysis. If we wish to make the 17 UN Sustainable Development Goals (SDGs) part of analysis, then multidimensional thinking is needed. PA is an attempt to avoid the "monetary reductionism" of CBA in favor of an analysis where monetary and non-monetary impacts (of different kinds) are separated and where, particularly on the non-monetary side, issues of inertia and irreversibility of impacts are observed.
\end{abstract}

Keywords: democracy; political economics; political economic person; ideological orientation; narrative; decision-making; matching; neoclassical economics; cost-benefit analysis; institutional ecological economics; positional analysis

\section{Introduction}

Politicians need to know reasonably well what they are doing when advocating specific investments in energy systems, construction of houses, roads, dams, etc. Other actors such as those affected or concerned also need to be informed about what is going on. Mainstream economists claim expertise in this situation and advocate so called cost-benefit analysis (CBA). This is a method where costs and benefits are understood in monetary terms. Non-monetary impacts of specific alternatives are transformed to their alleged monetary equivalents and all impacts are aggregated. The analyst is then able to compare the alternatives considered in one-dimensional monetary terms. The alternative with the highest estimated profitability is recommended to politicians (or other decision-makers) and to other concerned actors more generally.

The analyst using CBA claims expertise in an extreme sense. He or she knows about the method to be applied, correct prices of different costs and benefits as well as the correct discount rate when aggregating impacts that refer to different future periods of time.

When discussing approaches or methods as possible alternatives to CBA, such methods are often expected to be similar to CBA in the sense of producing one alternative as the "best" in one-dimensional terms, for example, using an index. The very idea of a "method" is perhaps cognitively understood as something that clearly discriminates among alternatives to produce the best or optimal outcome. 
In this essay, the roles of the analyst as well as the decision-maker or other actor will be different in fundamental respects. Rather than one-dimensional analysis, a kind of multidimensional approach will be proposed and rather than limiting attention to values in terms of correct market prices according to CBA, an attempt is made to consider different viewpoints in terms of ideological orientation that appear relevant among decision-makers and others concerned. Conclusions will then be conditional in relation to each viewpoint or ideological orientation considered.

\section{Two Kinds of Reductionism in Neoclassical CBA}

Investments in infrastructure of the kind exemplified are complex in many respects. How should one as an analyst deal with this complexity? Should one accept some part of the complexity or simplify the analysis? Gareth Morgan, an organization theorist, makes the following observation:

"We live in a world that is becoming increasingly complex. Unfortunately our styles of thinking rarely match this complexity. We often end up persuading ourselves that everything is more simple than it actually is, dealing with complexity by presuming that it does not really exist" [1]

Neoclassical CBA is a far-reaching attempt to reduce complexity in two respects to make analysis more tractable:

- Impacts that normally are multidimensional are reduced to one-dimensional monetary impacts, so called "monetary reductionism";

- Many voices and ideological orientations in a democratic society are reduced to one ideological orientation, more precisely the one built into CBA. This can be referred to as "ideological reductionism".

CBA and neoclassical economics more generally are built on a "trade-off philosophy", where different kinds of impacts can be traded against each other. There is a monetary price for everything. Environmental or health impacts can be compensated for with monetary impacts, for example. This is a dangerous philosophy. Non-monetary impacts are then no longer respected and made visible in their own terms but tend to disappear in a one-dimensional calculation.

As already indicated the alternative approach is to avoid trade-off philosophy of the kind exemplified by CBA and instead identify expected non-monetary impacts and make them visible as well as possible. Such impacts can be described in multidimensional profile terms.

Why abandon this one-dimensional thinking and analysis, one may argue, which makes life easier for the analyst as an expert and also for politicians who can refer to the results of (what is considered as) scientific studies? In a democracy politicians need to be well informed about what they are doing and particularly on the non-monetary side there are aspects of inertia and irreversibility to be considered and made visible. Biodiversity losses, climate change, land-use changes and changes in health status exemplify areas where inertia and irreversibility need to be observed. In the case of climate change, the irreversible impacts of $\mathrm{CO}_{2}$ pollution were for a long time largely neglected by politicians and others responsible. How can one deal with climate change in CBA? A price which is infinite because of irreversibility, I would suggest. Alternatively, the analyst may argue for a price connected with a specific market for pollution permits (socially constructed on the basis of advice from neoclassical economists). However, how fair or reasonable is it to suggest a limited price for irreversible negative impacts upon future generations locally and globally?

Why "democracy-oriented" analysis? Again, the weaknesses of CBA can be used as a point of reference. CBA can be described as a "technocratic" approach where the analyst as an expert is believed to be equipped with the capability to determine what is "best" for society as a whole. Politicians are expected to accept the result of analysis and other actors may have their opinions but are expected to accept what is presented by the analyst with her/his claimed scientific method.

There is a long tradition of attempts to clarify the meaning of democracy. It may be argued that human rights such as freedom of speech are an essential part of democracy and that therefore each 
citizen has the right to advocate her specific interpretation of democracy. However, in any society there is a need for consensus about essential characteristics of a democratic society.

Introducing democracy seriously into the economics discipline, dominated as it is by neoclassical theory, has far-reaching consequences. Ideas of individuals exclusively related to markets, so called Homo Oeconomicus assumptions, have to be abandoned. The individual is regarded as an actor interacting with other actors (individuals and organizations) and is guided by ethical as well as ideological consideration within and outside markets. This will be referred to as "political economic person" assumption in the pages to follow.

In a democracy, human rights are observed. They include freedom of speech and freedom of organization. Politicians and citizens can be members of different political parties and there are rules for decision-making in public assemblies, for example, majority voting. As part of the power structure of a democracy, an independent legal system exists to avoid corruption and other abuse of power.

For present purposes of discussing the assessment of public projects, three related aspects of democracy will be emphasized:

- $\quad$ Listening to many voices;

- Facilitating participation in dialogue about the planning and decision process;

- Respecting different views and more generally, trust and fairness in relationships between individuals and organizations as actors.

While the neoclassical CBA perspective essentially relies on one actor, the analyst, the alternative is to encourage affected and concerned actors to participate in dialogue about visions, alternatives and expected impacts. Conflicts of interest and tensions between stakeholders and actors with different ideological orientations should be respected. It is believed that open dialogue generally increases the probability of decisions-and the implementation that follows-to be justified and regarded as legitimate among a large proportion of the citizens in the relevant community.

\section{Redefining Economics in Terms of Multidimensional Analysis and Democracy}

In neoclassical introductory textbooks, economics is normally described as "the study of how society manages its scarce resources" [2]. Economics is about decision-making or "allocation" of limited resources. In practice, this often leads to one-dimensional monetary calculation as in CBA or at best two-dimensional thinking and analysis in "cost-efficiency" terms. The ambition is then to minimize the monetary cost of achieving a specific non-monetary objective.

I have at various places [3-5] proposed a new definition of economics that still focuses on decision-making but clarifies further the kind of analysis that is needed at the level of society:

"Economics is understood as multidimensional management of limited resources in a democratic society"

This definition follows from the previous arguments about the need for a multidimensional analysis and also a need for a democratic procedure, different from the technocratic tendency in CBA. Since 2015, the United Nations has sanctioned no less than 17 Sustainable Development Goals (SDGs) with targets or sub-goals for each one of them. Not all SDGs are relevant in a specific decision situation but normally more than two goals. In a democracy, each actor as a citizen or decision-maker considers some of the SDGs in her "ideological orientation". Further, actors may agree or disagree about what is important or best for society to do in the decision situation.

As argued previously, the new idea of economics as a discipline needs to be followed by a conceptual framework consistent with the new definition:

- Neoclassical economic man (Homo Oeconomicus) is replaced by a political economic person (PEP);

- Neoclassical profit-maximizing firm is replaced with a political economic organization (PEO);

- Markets in terms of supply and demand (as in neoclassical theory) are instead understood as relationships and networks between PEPs and PEOs; 
- Concerning the assessment of projects at various levels, neoclassical cost-benefit analysis (CBA) is replaced with positional analysis (PA).

Politics and policy are no longer limited to the choice of measures at the level of the state to achieve certain goals. All individuals and organizations are political actors and potentially involved in influencing development processes. Politics starts with individuals and organizations in different roles and situations. Further, political change is influenced by many factors including our ideas about economics as a discipline.

\section{A Return to "Political Economics"}

Classical economists such as Adam Smith, David Ricardo and John Stuart Mill were conscious about the moral and political content of their work. Smith is known for his reference to "the invisible hand" in rather mechanistic terms but also wrote a book, "Theory of Moral Sentiments", published in 1759, which suggests that he was aware of the ethical and political aspects of economics. Later, David Ricardo and John Stuart Mill referred directly to political economy in the titles of their books. Ricardo's "Principles of Political Economy and Taxation" was published in 1817 and Mill's "Principles of Political Economy" in 1848 [6].

This terminology was dominant until about 1870 when what is now called neoclassical economics was born. Since then, it is believed that value-neutrality is possible and that economics can be a science much like physics. The political content and influence of the neoclassical paradigm was denied or downplayed and accordingly the title of textbooks became just "Economics".

In more recent times, those who refer to Marxist criticism of capitalism have attempted to monopolize the term "political economics" when presenting their perspective, but the argument here is that each kind of paradigm (school of thought) in economics is a kind of political economics. This is true of neoclassical economics as well as the kind of "institutional ecological economics" presented in this paper. What is added here is a reference to pluralism and democracy. We should avoid understanding one school of thought as the single possibility.

\section{5. "Ideological Orientation" as Key Concept}

In neoclassical texts, self-interest is assumed for the individual (and expected by the individual?). For the only kind of organization considered in neoclassical theory, the firm, similar narrow interests are assumed. Profits for shareholders should be maximized.

That narrow interests often exist and are very real is not questioned. It is certainly convenient to simplify analysis to make it tractable in mathematical terms and to give results an appearance of science and expertise. However, why eliminate broader considerations from the very beginning? When sustainability issues are concerned, for example, we expect actors in various roles sometimes to also think and act beyond self-interest and monetary considerations. Focus exclusively upon financial interest may even be part of the problems faced.

Politics is about ethics and ideology among other things. However, those who try to hide behind value-neutrality tend to avoid a vocabulary in terms of ideology. Among economists there are exceptions however. Joan Robinson with her early book "Economic Philosophy" is one. She does not hesitate to use the concept "ideology" and draws attention to the resemblance between the ruling ideology in society and the ideology of mainstream economics:

"We must go around to find the roots of our own beliefs. In the general mess of notions and sentiments that make up an ideology those concerned with economic life play a large part, and economics itself (that is the subject as it is taught in universities and evening classes and pronounced upon in leading articles) has always been a vehicle for the ruling ideology of each period as well as partly a method for scientific investigation" [7]

Among economists publishing in more recent times, Douglass North uses the concept "ideology" as follows: 
"By ideology I mean the subjective perceptions (models, theories) all people possess to explain the world around them. Whether at the microlevel of individual relationships or at the macrolevel of organized ideologies providing integrated explanations of the past and the present, such as communism or religions, the theories individuals construct are colored by normative views of how the world should be organized." (emphasis in original) [8]

Other terms similar to "ideology" can be used. Mary E. Clark, a professor of conflict resolution, refers to "worldview". Worldview is described as "constructed Gestalt". While there is some diversity of perspectives, reference can be made to a "Western world view" dominant in large parts of the world:

"All human thought, all our knowledge ultimately is grounded in certain "givens"—certain inescapable beliefs and assumptions. On them we construct our model of reality or "truth" that allows us to function with confidence, more or less automatically." [9]

A third concept in addition to worldview or ideology is "narrative". Essentials of a worldview or ideology can be described as a narrative or story about history, present situation and a desired future. Neoclassical economics with its emphasis on self-interest of individuals, profits in business and GDP growth is such a narrative. While those who believe in neoclassical theory probably try to encapsulate "sustainable development" into their worldview and narrative as "sustainable economic growth" and "sustainable profits in business" (where some broader interest can be included), I see sustainable development in the UN sense of the 17 SDGs as elements of a different story-line or narrative.

As a way of summarizing this section, it is argued that just as politicians refer to their ideologies, ideological orientations or narratives in attempts to convince us as citizens, something similar may hold for actors in other roles. As citizens, we respond to the appeals of politicians. This suggests that something that can be referred to as "ideological orientation" is relevant also at the level of individuals as citizens in a democratic society.

Actually, an individual is understood as a "political economic person" (PEP) and actor guided by an ideological orientation in market as well as non-market contexts. Similarly, an organization is understood as a "political economic organization" (PEO) and actor guided by its ideological orientation or "mission". Neither ideological orientation, nor mission are understood in precise mathematical terms. Parameters that can be quantified are certainly involved but also qualitative and visual elements. An ideological orientation may be fragmentary and uncertain. Tensions between motives are often involved. No rigid idea about the content of the ideological orientation of all individuals, all consumers or the mission of all organizations is assumed. This is an open issue and something to be investigated in each case [10]. There are certainly organizations focusing narrowly on monetary profit but also numbers of political economic organizations largely related to non-monetary goals such as the $17 \mathrm{UN}$ SDGs. Greenpeace is here suggested as an example of this latter kind of organization [11]. It is a strange fact of life that organizations of this kind are not mentioned in neoclassical textbooks, suggesting one more time that ideological orientation is involved.

\section{Why Positional Analysis?}

Individuals and organizations in their political and other roles often understand problems and decision situations differently. Such differences of opinion should be respected in a democracy. The kind of economics advocated in this essay can be used in more general terms as a conceptual framework, way of thinking, arguing and acting in relation to planning and decision-making issues at different levels including a public level. Positional analysis can also be regarded as an attempt to construct a method that is helpful in this situation with actors who differ more or less with respect to ideological orientation or missions.

Rather than assuming consensus about ideological orientation/missions among all actors as in CBA, differences in ideological orientation are respected. The purpose of a PA then is one of illuminating an issue in a many-sided way with respect to: 
- Ideological orientations of actors affected (as stakeholders) or concerned;

- Alternatives of choice;

- Impacts of each alternative.

By respecting differences of opinion in the study concerning ideological orientation, alternatives and impacts, a PA study at the same time aims at strengthening democracy locally, nationally and globally. The ambition is to also contribute to learning processes of the actors, perhaps even innovative procedures for solving problems that while understood differently, have elements in common. Emphasis on democracy and an open decision process at the same time reduces possibilities of manipulation.

Many-sidedness in the illumination of ideological orientations suggests that it is not enough to refer to one single ideological orientation or narrative and not even two ideological orientations that are very close. Alternatives that differ in kind on the other hand are welcome. In relation to agriculture, one may refer to "industrial agriculture" with its ideas about efficiency and quality of product as one narrative and to "ecological agriculture" with its different ideas of performance. Similarly, "industrial forestry" and "ecological forestry" can be considered as two different narratives.

At the level of alternatives, "many-sidedness" means that the analyst (and other actors) is ready to consider alternatives that differ in kind and even alternatives advocated by groups in society that are weaker in power terms and less established. In practice, there are often limits to the number of alternatives that can be considered, perhaps three or four.

At the level of impacts, many-sidedness as ambition means that the tendency to emphasize monetary or financial impacts is counteracted. All kinds of impacts are potentially relevant and issues of inertia, such as irreversibility, should not be neglected. Alternatives and impacts can be illuminated in multiple decision stages using decision trees and in other ways [10].

The opposite of many-sidedness is of course one-sidedness. Only one ideological orientation is taken seriously, only one alternative and only one kind of impact are considered. Sometimes one actor (or actor category) is closing the door for competing ideas about ideological orientation, the project alternative to be implemented and impacts to be considered.

Master planning in the city of Uppsala these days can be given as an example. The coalition of political parties in power is preparing exploitation for housing purposes in the southern parts of the municipality. They welcome a considerable increase in the number of habitants. In an area now with 10,000 inhabitants, they plan for 60,000 additional persons. Urbanization is looked upon as a force that one has to accept. Everything seems to be based upon one ideological orientation that can be described as "sustainable growth" of the city. One single alternative expressed in terms of maps of land-use, etc., is presented albeit with openings for marginal modifications. On the positive side, it can be noted that impacts of the single alternative presented have been investigated in a many-sided way.

The political leadership in the city certainly has the right to emphasize one narrative and one basic alternative of choice. However, considering other narratives and alternatives, for example, with a smaller number of dwellings, might lead to a more constructive dialogue.

\section{Decision-Making as “Matching"}

The behavior of actors as political economic persons is largely habitual. In the case of political economic organizations, there are routines, i.e., established ways of acting in specific situations. Further, decisions in the sense of conscious choice between alternatives are made both at the individual and organizational level. Some of those decisions are largely or completely based on quantitative considerations. When comparing products in a shop with expected similar quality, an actor may choose the product with a lower price. Alternatively, the other way around: an actor in a similar situation may choose the alternative with the higher price, believing that this is a sign of better quality.

However, looking upon decision-making in exclusively quantitative terms is probably not the best way of understanding what goes on in society. When introducing a broader set of considerations, the idea of optimal solutions in quantitative terms can be looked upon as a special case while the idea of "matching" enters as a new way of understanding decision-making. Again, an actor's ideological 
orientation plays a key role in the sense that it is "matched" against the multidimensional expected impact profile of each alternative considered in the decision situation. Qualitative aspects and visual elements such as images are part of the ideological orientation and also of expected impacts. Before buying a house, you want to visit and see it indoors as well as in its external context. Sometimes, there is a good match between the actor's ideological orientation (including desired impacts) and expected impacts. Other words can be used. Among organization theorists, James March refers to "the logic of appropriateness" [12]. In our language, an alternative may be appropriate (or not appropriate) in relation to an actor's ideological orientation. In computer language, reference can be made to "pattern recognition". The ideological orientation of an actor is a desired pattern which is related to the expected pattern of impacts of an alternative.

Once more, it should be observed that ideological orientation and also expected impacts are often fragmentary and uncertain. Search processes can be initiated to further clarify ideological orientation as well as impacts.

\section{Essential Elements of a PA-Study}

Political economic person, political economic organization and other parts of the conceptual framework that have been presented in the form of an "institutional ecological economics" can be used for decision-making purposes without any documented study. However, in a democracy, it is an advantage if written documents are prepared. Such documents represent a basis for dialogue and can clarify commonalities and conflicts of interest as well as responsibilities. The roles of different actors become visible. Hopefully the discourse also implies a better result in the sense of acceptance and being seen as legitimate among many actors and citizens.

Positional analysis in the sense of an analyst systematically preparing decisions in written form has been presented elsewhere $[3,13]$. Here, some essential characteristics of a PA study will be discussed. Once more, the approach will be compared to CBA. Hopefully, not only analysts as professionals but also affected and concerned actors as well as decision-makers will find it meaningful to "internalize" some of the following elements of PA and "demand" an economics and approach to decision-making more in line with democracy.

\subsection{Decision Making in Relation to the Time Axis}

In neoclassical theory, an equilibrium between supply and demand is discussed for specific points in time. There is not much interest, neither in historical background nor in future developments (more than the expectation that one state of equilibrium is followed by another). Neoclassical CBA is different. There is similarly little interest in the history behind a decision situation. What matters is the future and the future is dealt with in monetary terms where all kinds of impacts can be traded or exchanged with each other as previously indicated. A discount rate is used when trading monetary impacts in different periods against each other. Further, a positive interest rate means that future impacts are downplayed, depreciated or discounted in relation to more immediate impacts. This is said to be in accordance with human nature.

When, on the other hand, preparing a PA study, history matters. The present situation is a product of previous developments, events and decisions. Are there historical documents and previous studies that can tell us about obstacles and openings in the present situation?

Financial and other monetary impacts in different future periods are certainly more or less important for different actors with their identities or ideological orientations. PA points specifically to non-monetary impacts in future points in time. Inertia of various kinds is considered. Are specific impacts reversible or irreversible? The mentioned "trade-off philosophy" of CBA has made many irreversible impacts (land-use changes, $\mathrm{CO}_{2}$ pollution) disappear in analysis. What is needed is an approach to decision-making in positional multiple steps. Is a move from a position in land-use at point in time $\mathrm{t}_{0}$ to a new position at $\mathrm{t}_{1}$ reversible or irreversible? 


\subsection{The Political Situation}

All decisions are regarded as potentially political. Individuals and organizations are political actors and refer to their ideological orientation or mission in contributing to society in broad terms as they wish. Positional analysis is however mainly constructed for decision-making at the societal level in local or national assemblies. The main ambition has been to present an alternative to CBA.

The analyst is expected to make actors more visible. Interested parties or stakeholders in relation to a decision situation can be identified as well as other actors with opinions about the issue. The analyst is expected to interact with stakeholders and other concerned actors as part of the problem-solving process. How do they understand problems? What are their ideological orientations and what kind of alternative(s) do they prefer? Ideally, this interaction is documented.

When making a study, the analyst also interacts with elected politicians or political parties to learn about their ideas of progress and preference for alternatives. This can be done in different ways. The analyst can go about the task herself/himself or can organize participation in committees or other ways (provided that this is accepted by politicians). Ideas from such interaction can add to analysis in the sense of a many-sided illumination of the issue. The final responsibility for decisions taken rests with the politicians and the relevant political assembly.

\subsection{Competing Ideas about Progress in Society}

CBA is based on one ideological orientation or narrative. Impacts should be valued in actual or hypothetical market terms. Prices and the monetary dimension are at the heart of analysis and results are expressed in terms of monetary profitability, much like estimates of profitability in a business corporation.

CBA is built upon an assumption that there is a consensus in society about the ideological orientation built into CBA. Ezra Mishan, himself a textbook author on CBA [14], later observed that such a consensus is not realistic and that the CBA method therefore should not be used when allocating resources at the public level [15]. Mishan, known also for the book "The Costs of Economic Growth" [16], precisely pointed to environmental issues that have become essential or decisive for an increasing part of the population.

In the case of PA, the recommendation is to listen to stakeholders, i.e., those affected in the decision situation (and also to those who are concerned while not directly affected) and try to identify ideological orientations that are relevant for these actors as PEPs and PEOs. In the extreme case, there may be consensus about one ideological orientation (mission or narrative) and one alternative, but in the normal case, competing ideological orientations will be perceived and considered in analysis.

Differences of opinion should not be hidden but instead made visible. Some tensions between single actors or groups of actors are believed to be constructive in the search for a better society. Such tensions may be reduced or increase as a result of dialogue. Reference is here made to an agonistic model of democracy where the ambition is to handle conflicts of interest with respect. This agonistic model $[17,18]$ can be contrasted with a consensus model of democracy. In neoclassical language, one may perhaps refer to an "equilibrium model of democracy" with mechanisms taking care of all kinds of tensions.

\subsection{Positional Thinking in Non-Monetary Terms}

As already made clear, CBA is criticized for its monetary reductionism and dubious way of considering future impacts. It is argued that the monetary "trade-off philosophy" is dangerous for society because non-monetary impacts are handled in ways that make them more or less invisible. While not seeing financial and other monetary impacts as unimportant, focus in "positional thinking" is on non-monetary impacts of different kinds.

Inertia in its various forms, such as path dependence, lock-in effects and irreversibility, is at the heart of analysis. Inertia in physical terms is an obvious phenomenon when land-use is transformed from agricultural purposes to house construction or new roads. Global positioning system (GPS) is an example where "path dependence" gets a clear meaning. As an individual, one is positioned in 
geographical terms for each point in time and there are limits as well as possibilities for future moves. Pollution of $\mathrm{CO}_{2}$ is an example where each unit of $\mathrm{CO}_{2}$ adds to our problems with climate change in an irreversible way.

However, inertia in positional terms can be relevant in many other dimensions, for example, when discussing the health status of an individual or a population. Actors connected with a business corporation can consider its "stock of knowledge" when comparing alternative research and development projects. Reference can also be made to "cognitive inertia" for me as economist or when studying my colleagues. Inertia is however not only something bad. Inertia is at the same time a matter of obstacles and opportunities. In a game of chess, one needs to think in more steps than one and each step means that some future steps are open, others excluded. There is irreversibility in the sense that regret is not possible. The analogy has its limits, however. A game of chess ends with one player as the winner while positional thinking can be seen as a never-ending process. Future positions as a result of present choices are starting points for new moves.

Thinking in multidimensional and positional terms means that the idea of one-dimensional quantitative analysis is abandoned. Some impacts in some dimensions are certain while a lot of uncertainty remains. Information about impacts is furthermore fragmentary rather than complete. However, the idea is that impacts are relevant for decision-makers and helpful in their ambition to know what they are doing.

Positional analysis also has potential implications for the control function and for extended kinds of accounting in business and other organizations. Accounting practices of an almost exclusively monetary kind has made life easy for many professionals in the accounting industry but has contributed massively to social and environmental problems that we now can observe. Non-monetary accounting practices of a more open kind need to be developed $[19,20]$.

\subsection{Systems Thinking}

Impacts can be estimated for future periods of time. However, when planning for a specific organization, for example, a city and a specific area, there is also an issue of space. Are impacts limited to one area or do they spill over to neighboring areas and in the extreme case the global society? $\mathrm{CO}_{2}$ is a typical example of global impacts in non-monetary positional terms.

In this part, "systems thinking" can be of help [21]. When considering a specific decision situation, the question may be asked if impacts are only affecting local systems, regional systems or even global systems. The assumptions often made that only local impacts count and that responsibility is limited to local impacts such as a city need to be reconsidered. In the example of using my car for a trip, there are kinds of pollution that are more local $\left(\mathrm{NO}_{\mathrm{X}}\right)$ and other kinds that extend to the global level.

\subsection{Conditional Conclusions}

Many actors expect experts to point to the "best" alternative and the right thing to do. However, what is right or wrong in a political decision situation is a matter of values and ideology, and in a democracy should finally be decided by politicians. In this situation, neoclassical economists enter the scene by telling us what ideology to apply and how to value each estimated impact in an aggregated analysis. One alternative comes out as the best for society as a whole.

In the case of PA, the way out of this dilemma is instead to accept the existence of actors with different ideological orientations in a particular society and among politicians. Relevant alternatives to be compared are identified on the basis of relevant ideological orientations rather than on the basis of one single ideological orientation. This means that the ranking of alternatives may (and probably will) differ depending on the ideological orientation considered. Some actors may prefer a no-change alternative, others may believe in an extreme economic growth narrative and some perhaps in a "sustainable growth" compromise.

It should be added that for a specific politician, it is possible that none of the ideological orientations systematically considered are close to her or his ideological orientation. In this case, it is believed that 
the many-sided analysis will still be helpful in illuminating the decision situation (and more helpful than a conventional CBA study in the same situation would be).

\section{Conclusions for a Democracy-Oriented Economics}

Is democracy taken seriously in mainstream economics textbooks? As an actor, one can take a look at the subject index in such textbooks and make a judgement. My perception is that the textbook writers regard "democracy" as being of limited relevance, perhaps as belonging to a different discipline.

In the present essay, democracy is regarded as being a necessary part of economics. This follows from the fact that "values are always with us", as argued by Gunnar Myrdal [22], and that each approach or school of thought in economics is specific in ideological terms. In a democracy, many voices should be heard. In the present situation where we have become locked into mainstream economics with a specific ideological orientation or narrative, it becomes extremely important to listen to visionaries [23,24]. When understanding that values and ideology are always present, the idea of relying on one single paradigm in economics becomes untenable and not compatible with democracy. Organizations that deny the ideological content of their theoretical or methodological perspectives cannot be taken seriously any longer. Actors within university departments of economics as well as journals in economics limited to the neoclassical paradigm have to reconsider what they are doing. Even the "Bank of Sweden Prize in Economics in Memory of Alfred Nobel" has to abandon its recent limitation to neoclassical theory. I believe that this neoclassical monopoly is among the explanatory factors when development nationally and globally has become increasingly unsustainable in important ways.

In a democracy, a kind of pluralism is normal. Since values differ, it should be considered as normal that many theories about markets exist [25] or many (partly overlapping) theories about multinational firms [26]. In this essay, a kind of institutional ecological economics has been presented. This is an economics in the tradition of the Journal of Economic Issues but with ideological emphasis on sustainable development in the sense of the 17 UN SDGs. Individuals are understood in political terms and the same is true of organizations. Even markets can be understood and assed for their performance in political terms. Focus in this study has been on decision-making at the public level where positional analysis has been proposed as alternative to CBA. A many-sided analysis has been advocated where the existence of competing ideological orientations in society has been taken into account. In this way, economics as a discipline can take some steps away from technocracy toward contributing to a strengthened democracy.

Funding: This research received no external funding.

Conflicts of Interest: The author declares no conflict of interest.

\section{References}

1. Morgan, G. Images of Organization; Sage: London, UK, 1986; p. 16.

2. Gregory, M.N.; Taylor, M.P. Economics, 2nd ed.; South-Western Cengage-Learning, EMEA: Andover, UK, $2011 ;$ p. 2.

3. Söderbaum, P. Mainstream economics and alternative perspectives in a political power game. In Positional Analysis for Sustainable Development. Reconsidering Policy, Economics and Accounting; Brown, J., Soderbaum, P., Dereniowska, M., Eds.; Routledge: London, UK, 2017; Chapter 3, pp. 22-28.

4. Söderbaum, P. Ecological economics: Redefining economics for democracy and sustainability. In Alternative Approaches to Economic Theory: Complexity, Post-Keynesian and Ecological Economics; Beker, V.A., Ed.; Routledge: London, UK, 2020; Chapter 9, pp. 207-221.

5. Söderbaum, P. Strategies in relation to complexities: From neoclassical Cost-Benefit Analysis to Positional Analysis. In Economic Philosophy: Complexities in Economics; Davis, J.B., Hands, W., Eds.; World Economics Association BOOKS: Bristol, UK, 2020; Chapter 2, pp. 75-92.

6. Gill, R.T. Evolution of Modern Economics; Prentice-Hall, Inc.: Englewood Cliffs, NJ, USA, 1967.

7. Robinson, J. Economic Philosophy; C.A. Watts \& Co Limited: London, UK, 1962; p. 1. 
8. North, D.C. Institutions, Institutional Change and Economic Performance; Cambridge University Press: Cambridge, UK, 1990; p. 23.

9. Clark, M.E. Search of Human Nature; Routledge: London, UK, 2002; p. 3.

10. Söderbaum, P. Economics, Ideological Orientation and Democracy for Sustainable Development, 2nd ed.; World Economics Association Books: Bristol, UK, 2018; pp. 26-40.

11. Bode, T. Die Diktatur der Konzerne: Wie Globale Unternehmen uns Schaden und die Demokratie Zerstören; S. Fischer Verlag: Frankfurt am Main, Germany, 2018.

12. March, J.G. A primer on decision making. In How Decisions Happen; Free Press: New York, NY, USA, 1994; pp. 57-59.

13. Brown, J. Positional analysis in relation to other pluralistic accounting practices. In Positional Analysis for Sustainable Development. Reconsidering Policy, Economics and Accounting; Brown, J., Soderbaum, P., Dereniowska, M., Eds.; Routledge: London, UK, 2017; Chapter 6, pp. 61-78.

14. Mishan, E.J. Cost-Benefit Analysis; Allen \& Unwin: London, UK, 1971.

15. Mishan, E.J. How valid are economic valuations of allocative changes? J. Econ. Issues 1980, 14, 141-161. [CrossRef]

16. Mishan, E.J. The Costs of Economic Growth; Penguin Books: Harmondsworth, UK, 1967.

17. Mouffe, C. The Democratic Paradox; Verso: London, UK, 2005.

18. Mouffe, C. Agonistics. Thinking the World Politicallly; Verso: London, UK, 2013.

19. Brown, J. Democracy, sustainability and dialogic accounting technologies: Taking pluralism seriously. Crit. Perspect. Account. 2009, 20, 313-342. [CrossRef]

20. Brown, J.; Dillard, J.; Hopper, T. Accounting, accountants and accountability regimes in pluralistic societies: Taking multiple perspectives seriously. Account. Audit. Account. J. 2015, 28, 626-650. [CrossRef]

21. Clayton, A.M.H.; Radcliffe, N.J. Sustainability: A Systems Approach; Earthscan: London, UK, 1996.

22. Myrdal, G. Institutional Economics. J. Econ. Issues 1978, 12, 771-783. [CrossRef]

23. Kras, E. The Blockage: Rethinking Organizational Principles for the 21st Century; American Literary Press: Baltimore, MD, USA, 2007.

24. Jakobsen, O. Transformative Ecological Economics: Process Philosophy, Ideology and Utopia; Routledge: London, UK, 2017.

25. Jackson, W.A. Markets: Perspectives from Economic and Social Theory; Routledge: London, UK, 2019.

26. Forsgren, M. Theories of the Multinational Firm: A Multidimensional Creature in the Global Economy, 3rd ed.; Edward Elgar: Cheltenham, UK, 2017. 